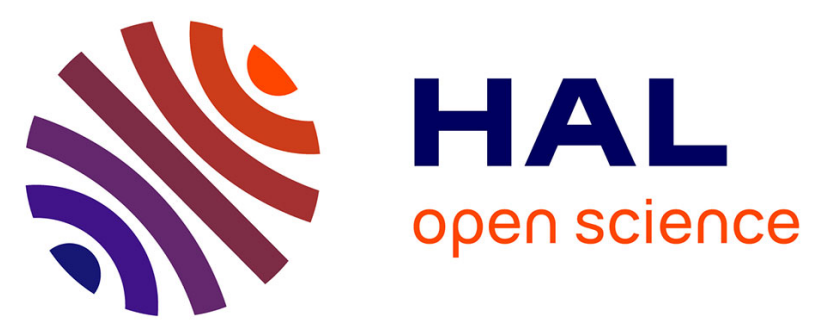

\title{
Transition saddle-cylinder shape of thin unsymmetric [0/90] square plates under hygrothermal loads: fringe projection method and variational approach
}

\author{
Marco Gigliotti, Frédéric Jacquemin, Jérôme Molimard, Alain Vautrin
}

\section{- To cite this version:}

Marco Gigliotti, Frédéric Jacquemin, Jérôme Molimard, Alain Vautrin. Transition saddle-cylinder shape of thin unsymmetric [0/90] square plates under hygrothermal loads: fringe projection method and variational approach. Applied Mechanics and Materials, 2005, 3-4, pp.217-222. 10.4028/www.scientific.net/AMM.3-4.217 . hal-01009069

\section{HAL Id: hal-01009069 \\ https://hal.science/hal-01009069}

Submitted on 20 Oct 2017

HAL is a multi-disciplinary open access archive for the deposit and dissemination of scientific research documents, whether they are published or not. The documents may come from teaching and research institutions in France or abroad, or from public or private research centers.
L'archive ouverte pluridisciplinaire HAL, est destinée au dépôt et à la diffusion de documents scientifiques de niveau recherche, publiés ou non, émanant des établissements d'enseignement et de recherche français ou étrangers, des laboratoires publics ou privés. 


\title{
Transition Saddle-Cylinder Shape of Thin Unsymmetric [0/90] Square Plates under Hygrothermal Loads: Fringe Projection Method and Variational Approach
}

\author{
M. Gigliotti ${ }^{1}$, F. Jacquemin ${ }^{2}$, J. Molimard ${ }^{3}$ and A. Vautrin ${ }^{3}$ \\ ${ }^{1}$ Centro Italiano Ricerche Aerospaziali, Via Maiorise 81043 Capua, Italy, m.gigliotti@cira.it \\ ${ }^{2}$ Laboratoire d'Application des Matériaux à la Mécanique, Université de Nantes, Boulevard de \\ I'Université,BP406, 44602 Saint-Nazaire, France, jacquemin@univ-nantes.fr \\ ${ }^{3}$ Département MEM, Centre SMS, Ecole Nationale Supérieure des Mines de Saint Etienne, 158 \\ Cours Fauriel, 42023 Saint-Étienne, Cedex 2, France, vautrin@emse.fr
}

Keywords: Nonlinear deformations; Unsymmetric 0/90 plates; Hygrothermal loads; Fringe projection method

\begin{abstract}
The deformation of free laminated plates subjected to transient hygrothermal loading is simulated by using a semi-analytical non linear model (variational method). A full-field experimental technique, the fringe projection method, has been developed to measure out-of-plane displacements throughout the deformation process. The experimental approach based on a full-field optical method is shown to be suited to capturing the complex behaviour of plates submitted to large hygrothermal loads, where geometrical nonlinearities should be taken into account.
\end{abstract}

\section{Introduction}

A large class of laminates deform even under uniform hygrothermal fields, as these fields produce thermal forces and bending moments. This behaviour is due to the ply arrangement and is reported as thermoelastic coupling. A typical example is given by laminates of the $0 / 90$ family: if a negative temperature differential is imposed on the laminate, as for the case of cooling from cure temperature, the $90^{\circ}$ plies tend to "shrink" more than the $0^{\circ}$ plies. Compatibility of displacements requires, for a perfect interface, that the plies must be "glued" during the entire process: therefore compressive and tensile stresses are generated in the $0^{\circ}$ and in the $90^{\circ}$ plies. To counteract the effect of such stresses, the laminate tends to deform. For a 0/90 laminate the deformed shape, according to the classical lamination theory, is a saddle, that is, its out-of-plane deflections with respect to a $(x, y, z)$ reference frame are described by a function:

$$
w(x, y)=-\frac{1}{2}\left(a x^{2}+b y^{2}\right)
$$

where $a$ and $b$ are parameters dependent on material properties and on the applied temperature differential. It can be seen experimentally that the deformed shape of cured $0 / 90$ unsymmetric plates with $\mathrm{e}_{0}=\mathrm{e}_{90}$ (the thickness of the plies are the same, $\mathrm{e}=\mathrm{e}_{0}+\mathrm{e}_{90}$ is the total thickness of the laminate) and with certain in-plane dimensions is not a saddle ([1], [2]). In place of the saddle shape $(a=-b)$, two cylinders, along the $x(a \neq 0$ and $b \approx 0)$ and the $y(b \neq 0$ and $a \approx 0)$ direction, exist: one cylinder can be snapped into another by applying an external force. Explanations to this behaviour can be found by including geometrical nonlinearities, that is, nonlinear relationships between displacements and strains. This accounts for small strains but relatively large rotations which effectively are present in a 0/90 hygrothermally deformed shape, where out-of-plane displacements are large compared to one typical dimension of the plate, the thickness for instance.

0/90 unsymmetric laminates are largely used for measuring hygrothermal stresses in composite laminates ([2] - [7]). However, no convincing experimental techniques have been developed so far, especially for transient environmental conditions. In the next sections we will discuss a new 
approach to assess transient internal stresses in heterogeneous materials, such as composite laminates, by conveniently measuring the deflections of $0 / 90$ plates. The differences between this approach and existing methodologies and techniques will be shortly recalled and results for composite plates under transient environmental test conditioning will be presented.

\section{Model description}

Simulations of the hygrothermal internal stresses are performed by adopting an uncoupled approach: the hygrothermal fields are determined by applying classical Fourier and Fick laws [8], then stresses are evaluated by adopting linear elastic constitutive laws. At the structural level, the composite plates are modelled by a nonlinear (Foppl-Karman) model, which takes into account nonlinear strain-displacement relationships and by adopting a variational (energy-based) procedure. Solutions of the hygrothermoelastic problems satisfy the conditions:

$$
\left\{\begin{array}{l}
\delta E_{T}=0 \\
\delta^{2} E_{T}>0
\end{array}\right.
$$

where $E_{T}$ is the total potential energy of the plate. Conditions (2) have to be satisfied by a displacement field which is at least compatible with kinematics boundary conditions. The search for solutions may be started by using, as first suggested by Hyer [1], the displacement fields of the linear theory, equation (1): $a$ and $b$ are then seen as parameters which, for each value of temperature differential and moisture concentration, are established through (2).

The first condition of (2) gives equilibrium solutions, while the second condition assures the stability of such solutions: equation (1), although simple, offers a great variety of solutions, when $a$ $=-b$ the deformed shape is a saddle, when $a \neq 0$ and $b \approx 0$ the deformed shape is quasi-cylindrical and so on. An example of such an approach is schematically described in figure 1, where the evolution of the $a$ and $b$ parameters is presented, for a square plate, as a function of the temperature, starting from the stress-free temperature, at which the plate is assumed to be flat. Classical lamination theory gives the paths $\mathrm{A}-\mathrm{B}$, in which the $a$ and $b$ parameters are, for each value of temperature, of equal magnitude and opposite sign (saddle shape). Non-linear theory provides saddle-shaped deformed solutions until point $\mathrm{O}$, at which a bifurcation phenomenon occurs. In fact, the saddle shapes become unstable (path O-E), while quasi-cylindrical deformed shapes become available on stable post-bifurcation branches. For example, path O-C represents a deformed configuration with $a>0$ and $b$ which tends to zero increasing the temperature differential.

The deformed shape is progressively "more cylindrical" along the $x$ direction moving from high to low temperatures. Due to symmetry, a cylindrical deformed shape may develop along the $y$ direction (path O-D). The two deformed shapes have, in theory, the same energy content, thus they may both exist at a certain temperature. The appearance of one shape rather than the other is driven by the presence of imperfections. Analogous behaviour is found for laminated plates subjected to general hygrothermal conditioning: moisture absorption tends to counteract the effects observed in figure 1.Therefore, for instance, conditioning the plate while keeping the temperature constant at a value less than $T_{O}$ (the temperature at point $\mathrm{O}$ ), that is, beyond the bifurcation point, when the plate develops cylindrical deformed shapes, may promote again transition to saddle deformed shapes. This behaviour is strictly true for square plates with $\mathrm{e}_{0}=\mathrm{e}_{90}$. More complex behaviour has been observed and simulated for rectangular $0 / 90$ plates, even with $\mathrm{e}_{0}=\mathrm{e}_{90}[9]$.

\section{Fringe projection method for curvature measurements and experimental results}

A traditional experimental technique, which is widely used for $0 / 90$ specimens ([2]-[7]), consists in measuring the cord length, the height and the thickness of the samples and then, by assuming that 
the deformed shape is an arc of circle, calculating the curvature, which is the inverse of the radius of the circle.

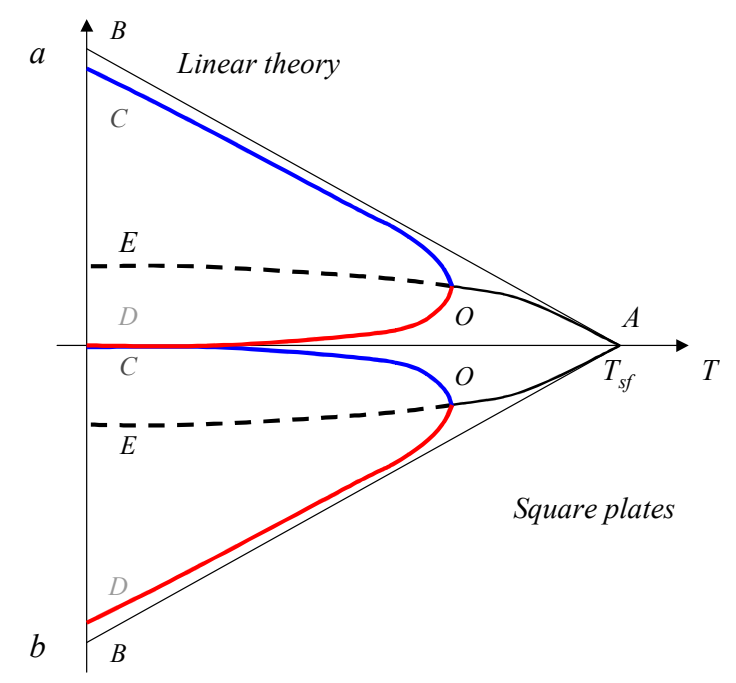

Figure 1: Evolution of the $a$ and $b$ parameters for a square 0/90 laminated plate as a function of temperature

This experimental technique makes assumptions on the deformed shape. Wu et al. [7] used the traditional 0/90 unsymmetric sample technique to develop a transient simulated methodology and to study temperature variations and moisture ingression in composite materials. However, their protocol consisted in weighting the samples and measuring their curvature periodically at room temperature: in fact, their technique implied measuring the samples after removing them from the water baths, and then blotting them dry, or by removing samples from ovens and cooling them to ambient temperature. Actually, this technique is not a "genuine" transient technique. Much of the information coming from the transient state, which is by definition a state evolving continuously with time, is lost by frequently removing the samples from the water conditioning or the oven. An improved methodology to characterise the transient thermal state was proposed by Gigliotti, Wisnom and Potter [2]. The deflection of $0 / 90$ samples is measured as a function of the temperature, the specimen lying in a oven. The measurement of out-of-plane deflections of 0/90 plates under hygrothermal loads has been further enhanced in the present work by using a full-field optical technique, the fringe projection method. This technique allows the whole displacement field of the plate to be measured and makes no assumptions of the deformed shape. The physical principle of the fringe projection method is very simple: some fringes, a periodic pattern of white and black lines, are projected on an object, the light is diffused by the object and captured by a CCD video-camera, see figure 2.

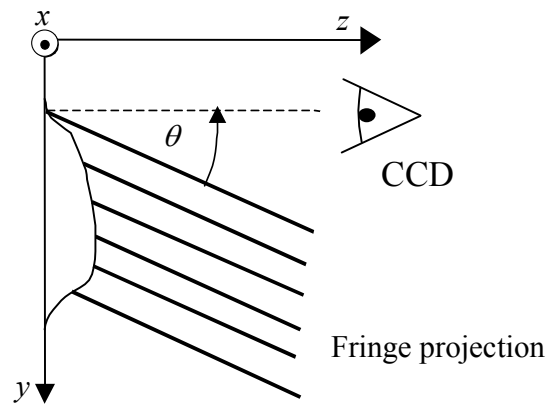

Figure 2: Principle of the fringe projection method 
Differently from deflectometry, the fringe projection technique exploits the light diffused by an object in order to measure its deformation: therefore, the object must diffuse the light sufficiently. Moreover, in order to observe out-of-plane displacements, the angle between the projected fringes and the observed diffused light must be non-zero. When an object is illuminated by a set of fringes the light intensity is described by a function:

$$
I_{l i}(x, y)=I_{0}(x, y)\left[1+\gamma(x, y) \cos \left(\frac{2 \pi}{p} y+\phi(x, y)\right)\right]
$$

characterised by an average intensity $I_{0}$, the pitch, $p$, which is the distance between two light peaks, and the contrast, $\gamma$. The object is responsible for a phase shift $\phi=\phi(\mathrm{x}, \mathrm{y})$ at each point of the field. Relation (3) is based on three unknown quantities $\left(I_{0}(x, y), \gamma(x, y), \phi(x, y)\right)$ which need at least three equations to be identified. The phase is extracted through the computer code Frangyne [10] and the out-of-plane position $w(x, y)$ can be calculated according to the following basic equation:

$$
\phi(x, y)=2 \pi \frac{\tan (\theta)}{p} w(x, y)
$$

In this expression the sensitivity, that is the slope of the linear relationship between $\phi(x, y)$ and $w(x, y)$, can be adjusted by modifying the pitch $p$ or the angle $\theta$ between the CCD video-camera and the video-projector. It has to be noted that the previous equation is obtained by assuming that the rays of light are parallel to each other, thus the angle $\theta$ is assumed to be constant over the whole spatial field, see figure 2 .

The fringe projection method is applied to hygrothermally deformed thin $0 / 90$ free plates: THR180/EH84 carbon/epoxy composite plates under pure thermal stress and hygrothermal stress. The experimental set-up is shown in figure 3. A set of $j$ fringe patterns, each shifted by an amount equal to $2 \pi / j$, are projected sequentially by a video-projector onto the plate (patterns are slides of a PowerPoint presentation) and serves the phase extraction algorithm. The images diffused by the plate are captured by a CCD video-camera connected, in turn, to a personal computer where the Frangyne code extracts the phase field. Finally, the displacement field (equation 4) is obtained. A Basler A113P (1296* 1030 pixels, 8 bits) CCD video-camera was employed.

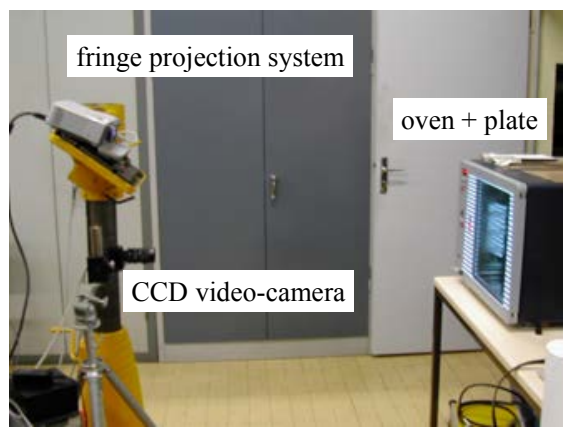

Figure 3: Principle of the fringe projection method

The THR180/EH84 $\left[0_{2} / 90_{2}\right]$ plate (average dimensions: $120 \mathrm{~mm} * 120 \mathrm{~mm} * 0.6 \mathrm{~mm}$ ) was fabricated at a cure temperature $\mathrm{T}_{\text {cure }}=120^{\circ} \mathrm{C}$ in one $90 \mathrm{~min}$ temperature dwell. The temperature ramp to reach cure temperature was $3^{\circ} \mathrm{C} / \mathrm{min}$. The applied pressure was 7 bars. Immediately after cure, the sample was placed in an oven where the temperature was raised from $T_{\text {amb }}$ to $T_{\text {cure }}$ and the evolution of its shape was monitored via the optical apparatus. Before testing, the side exposed to the light was painted in white in order to be sufficiently diffusive. During the test, the plate temperature was measured by a temperature gauge situated very close to the sample surface. Experimental results show that when the plate is subjected to a small temperature differential $(\Delta \mathrm{T} \approx$ 
$-5^{\circ} \mathrm{C}$ ), the deformed shape is a saddle (figure $4 \mathrm{a}$ ). Figure 4 shows the experimental shape (on the left), the numerical approximation obtained by fitting all the experimental points by a second-order polynomial approximation (at the centre) and the absolute error between the two (on the right). The error is very small across the whole field, with the exception of a few zones, the deformed shape is a saddle with very good approximation. When the temperature differential is higher $\left(\Delta \mathrm{T} \approx-90^{\circ} \mathrm{C}\right)$ the deformed shape is cylindrical (figure 4b). Qualitatively, measured shapes are in good agreement with predictions from the Rayleigh-Ritz model, which assumes a second-order polynomial approximation to describe out-of-plane displacements: moreover, shape transition effectively occurs at a certain temperature (or temperature differential).
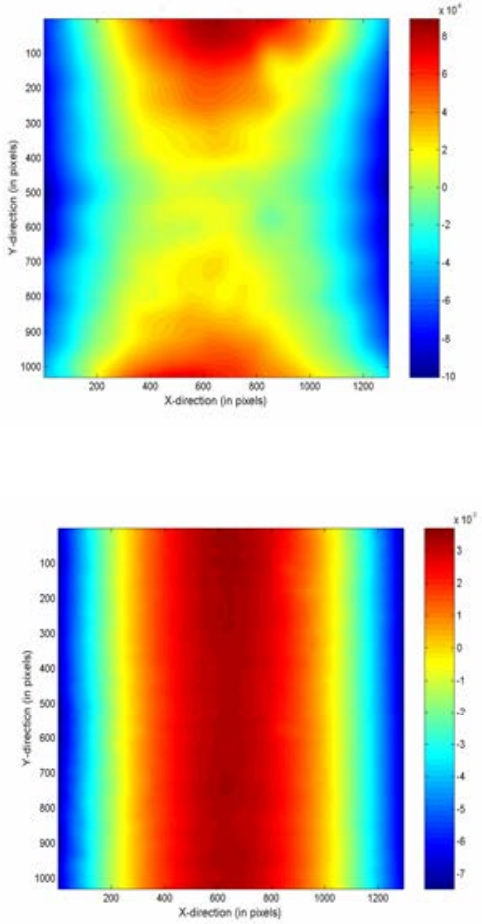

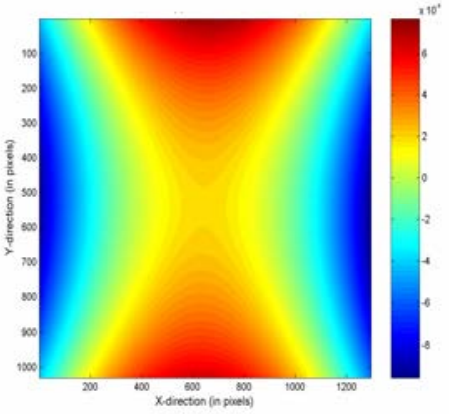

(a)

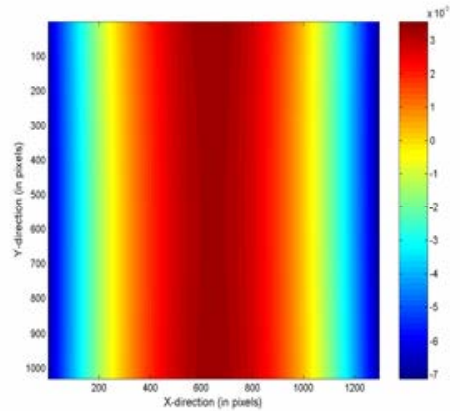

(b)
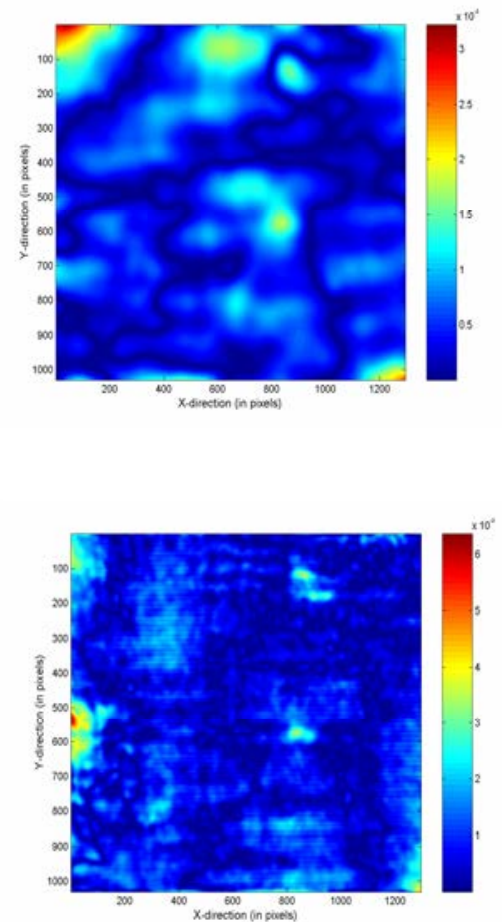

Figure 4: Experimental, numerical (experimental point fitting) shape and error between the two for a $0 / 90$ plate subjected to (a) $\Delta \mathrm{T} \approx-5^{\circ} \mathrm{C}$ and (b) $\Delta \mathrm{T} \approx-90^{\circ} \mathrm{C}$

Figure 5 shows the evolution with temperature of the parameters $a$ and $b$, as extracted by fitting the experimental results. The $a$ and $b$ curvatures are actually of opposite sign but are reported in only one picture for clarity. In this curve, the transverse coefficient of thermal expansion, $\alpha_{2}$, was identified by adjusting the numerical curve in order to fit the experimental points $\left(\alpha_{2} \approx 37 \cdot 10^{-6}{ }^{\circ} \mathrm{C}^{-}\right.$ ${ }^{l}$ ). The temperature at which the solution bifurcates seems to be well captured by the experiments, the transition saddle - cylinder is confirmed, even though it is not clear whether the transition is as abrupt as predicted by the theory. From a quantitative point of view some discrepancies are visible, but the trend is very good. This kind of test has been extended to plates under hygrothermal stress, the results of which will be presented soon.

\section{Conclusions}

The fringe projection method is a valuable technique to measure nonlinear hygrothermoelastic deflections of 0/90 plates. Predictions are made by a geometrically nonlinear model of plates, which captures the quite complex behaviour of such plates under hygrothermal loads. The variationalbased procedure consists in assuming the shape of the out-of-plane deflections and determines such deflections by the principle of total potential energy minimization. Out-of-plane displacements are then measured by the fringe projection method. The first experimental verification consisted in assessing the pertinence of the assumed shapes, which was found to be qualitatively very good. Also 
the quantitative agreement between the model and the measured deflections was good, for plates under both pure thermal and hygrothermal conditioning. Moreover, the use of 0/90 laminated plates coupled with the variational model can be foreseen for identifications of material parameters, e.g. the thermal and hygroscopic coefficients of expansion.

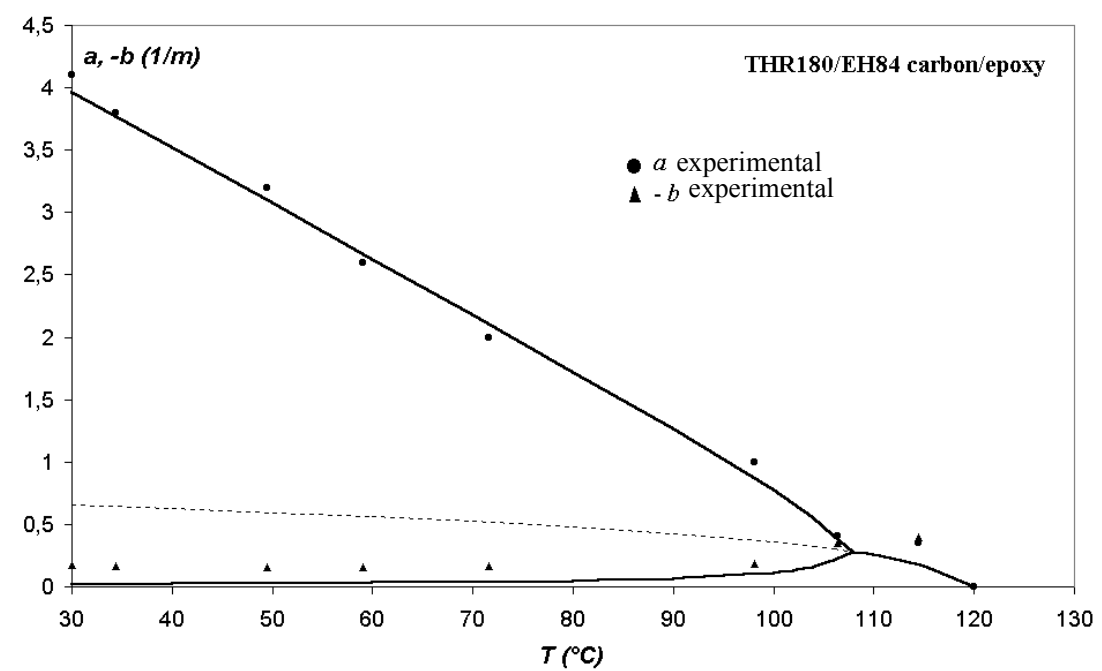

Figure 5: Numerical and experimental $a$ and $b$ parameters for carbon-epoxy material

\section{References}

[1] Hyer M.W. "Calculations of the Room-Temperature Shapes of Unsymmetric Laminates" Journal of Composite Materials, Vol.15 (1981), p.296

[2] Gigliotti M., Wisnom M.R., Potter K.D. "Development of Curvature during the Cure of AS4/8552 [0/90] Unsymmetric Composite Plates" Composites Science and Technology, Vol.63 (2003), p.187

[3] Kim K.S. Hahn H.T. "Residual Stress Development during Processing of Graphite/Epoxy Composites" Composites Science and Technology, Vol.36 (1989), p.121

[4] White S.R., Hahn H.T. "Process Modelling of Composite Materials: Residual Stress Development during Cure. Part II: Experimental Validation" Journal of Composite Materials, Vol.26 (1992), p.2423

[5] Sarrazin H., Kim B., Ahn S.H., Springer G.S. "Effects of Processing Temperature and Lay-up on Springback" Journal of Composite Materials, Vol.10 (1995), p.1278

[6] Tarsha-Kurdi K.E., Olivier P. "Thermoviscoelastic Analysis of Residual Curing Stresses and the Influence of Autoclave Pressure on These stresses in Carbon/Epoxy Laminates" Composites Science and Technology, Vol. 62 (2002), p.559

[7] Wu, Y. J., Takayota, T., Chung, K., Seferis, J. C. et Ahn, K., Development of the transient simulated laminate (TSL) methodology for moisture ingression studies using unsymmetric laminates, Journal of Composite Materials, Vol. 34 (2000), p.1998

[8] Carslaw H.S., Jaeger J.C. "Conduction of Heat in Solids" $2^{\text {nd }}$ Edition Oxford University Press 1974

[9] Gigliotti M., Wisnom M.R., Potter K.D. "Loss of Bifurcation and Multiple Shapes of Thin [0/90] Unsymmetric Plates Subject to Thermal Stress" Composites Science and Technology, Vol. 64, p.109, 2004

[10] Surrel, Y., Phase stepping: a new self-calibrating algorithm, Applied Optics, Vol. 32 (1993), pag.3598 


\section{References}

[2] Gigliotti M., Wisnom M.R., Potter K.D. "Development of Curvature during the Cure of S4/8552 [0/90] Unsymmetric Composite Plates” Composites Science and Technology, Vol.63 2003), p.187 doi:10.1016/S0266-3538(02)00195-1

[3] Kim K.S. Hahn H.T. "Residual Stress Development during Processing of Graphite/Epoxy omposites" Composites Science and Technology, Vol.36 (1989), p.121

doi:10.1016/0266-3538(89)90083-3

[4] White S.R., Hahn H.T. "Process Modelling of Composite Materials: Residual Stress evelopment during Cure. Part II: Experimental Validation” Journal of Composite Materials, ol.26 (1992), p.2423 doi:10.1177/002199839202601605

[5] Sarrazin H., Kim B., Ahn S.H., Springer G.S. "Effects of Processing Temperature and Lay-up on pringback" Journal of Composite Materials, Vol.10 (1995), p.1278

doi:10.1177/002199839502901001

[7] Wu, Y. J., Takayota, T., Chung, K., Seferis, J. C. et Ahn, K., Development of the transient imulated laminate (TSL) methodology for moisture ingression studies using unsymmetric aminates, Journal of Composite Materials, Vol. 34 (2000), p.1998

doi:10.1177/002199800772661949

[10] Surrel, Y., Phase stepping: a new self-calibrating algorithm, Applied Optics, Vol. 32 (1993), ag.3598 doi:10.1364/AO.32.003598

[2] Gigliotti M., Wisnom M.R., Potter K.D. "Development of Curvature during the Cure of AS4/8552 [0/90] Unsymmetric Composite Plates" Composites Science and Technology, Vol.63 (2003), p.187 doi:10.1016/S0266-3538(02)00195-1

[3] Kim K.S. Hahn H.T. "Residual Stress Development during Processing of Graphite/Epoxy Composites" Composites Science and Technology, Vol.36 (1989), p.121

doi:10.1016/0266-3538(89)90083-3

[4] White S.R., Hahn H.T. "Process Modelling of Composite Materials: Residual Stress Development during Cure. Part II: Experimental Validation" Journal of Composite Materials, Vol.26 (1992), p.2423 doi:10.1177/002199839202601605

[5] Sarrazin H., Kim B., Ahn S.H., Springer G.S. "Effects of Processing Temperature and Lay-up on Springback" Journal of Composite Materials, Vol.10 (1995), p.1278

doi:10.1177/002199839502901001

[7] Wu, Y. J., Takayota, T., Chung, K., Seferis, J. C. et Ahn, K., Development of the transient simulated laminate (TSL) methodology for moisture ingression studies using unsymmetric laminates, Journal of Composite Materials, Vol. 34 (2000), p.1998

doi:10.1177/002199800772661949

[10] Surrel, Y., Phase stepping: a new self-calibrating algorithm, Applied Optics, Vol. 32 (1993), pag.3598 